\title{
MITCHINER MEMORIAL LECTURE BLOOD IN WAR AND PEACE
}

\author{
MR. A. S. TILL, M.A., M.Chir., F.R.C.S.
}

Memorial lectures are founded for remembrance, and today we commemorate the life and work of Philip Mitchiner and especially all he did for the Army and Military Surgery, which of his many interests were those nearest to his heart. This lecture is a tribute twenty five years since he died, and reviews the changing role of blood in the treatment of battle casualties over the centuries. Wars and battles inevitably result in shedding of blood, but for some twenty centuries, blood letting was the standard practice in the treatment of wounds and sundry diseases of civilian life. Only in the last fifty years has blood transfusion replaced venesection and become one of the most outstanding advances in therapy. There is no branch of medicine in which doctors have so decisively stood on their heads.

On the evening of the Battle of Waterloo on $18 \mathrm{June}, 1815$, when the victorious Allies at last advanced against the disintegrating French Grand Army, twelve assistant surgeons found themselves left behind with no less than five hundred wounded among the farm buildings of Mont St. Jean. For that night and the following day they had neither food nor instruments for performing important operations. John Gordon Smith ${ }^{1}$ of the 12th Regiment of Dragoons records in his biography "that, while awaiting the arrival from Brussels of the requisite apparatus, they bled our poor fellows all around". This small incident, though it may appear somewhat trivial, does indicate the general teaching and practice with regard to blood letting at that time. The Low Countries, which have been called the cockpit of Europe, have also been the crucible in which many advances in the practice of military surgery and, subsequently, of civilian practice have had their origin. In 1945, one hundred and thirty years after the battle of Waterloo, there was a decided difference. Instead of bleeding the wounded, three-ton refrigerator lorries of the Blood Transfusion Units, with the familiar vampire emblem, were setting out from Brussels, carrying supplies of blood to the forward surgical units in the Reichwald Forest and for the Rhine crossing. The wheel had thus turned full circle.

\section{Venesection}

The origin of the practice of venesection is lost in the mists of time; a picture on an Attic vase from about 500 B.C. in the Louvre depicts a patient being bled.

Hippocrates laid down fairly precise indications for its use-infectious, hypochondria, pains in the liver and heaviness in the spleen and collections of humours such as pleural effusions. For these medical complaints perhaps the loss of blood might have done little harm.

-Given at the Royal Army Medical College, Millbank, London on 15 November, 1977. 
The underlying theory for the treatment of fevers, before their aetiology and pathology were understood in the latter part of the last century, was that fever was due to phlogiston, a hypothetical substance with which bodies were supposed to part when burning. The antiphlogistic regime advocated by our forebears in the treatment, and indeed prevention of fevers and inflammation, was the elimination of this substance by vomiting, purging and bleeding, to reduce the vascular action which is commonly manifest in the four cardinal signs of inflammation, assisted on occasion by the exhibition of such drugs as mercury, the bark (quinine) and antimonials. Prior to 1850 venesection or phlebotomy was the standard treatment for fevers, wounds and inflammation. Thomas Sydenham was much in favour of bleeding for fevers, as was Thomas Dover, physician and privateer who in his book "The Ancient Physician's Legacy to his Country" in 1742 recommended bleeding up to $100 \mathrm{oz}$. of blood in cases of plague.

Percival Pott was considered a heavy bleeder but John Hunter, as perhaps one might expect, was more moderate and in his work on "Inflammation and Gunshot Wounds"3, published posthumously in 1794, concentrated attention more on purging, quietude and a low diet in inflammation. Sir John Pringle ${ }^{4}$, the father of military medicine, during the same period was, however, an ardent believer in bleeding, "the most indispensable remedy in the cure of all inflammatory diseases". And, as late as 1852, Sir John Ballingall, ${ }^{5}$, Professor of Military Surgery in Edinburgh, wrote that "general blood letting has been universally admitted to be one of the most powerful remedies in inflammation". He bled a young soldier of the 33rd Regiment $52 \mathrm{oz}$. and $30 \mathrm{oz}$. ad deliquium, that is till unconsciousness, to cut short an attack of ophthalmia, which he considered it had accomplished.

In purely military surgery, venesection was the universal practice in all European armies for inflammatory conditions, notably those in cavities such as the cranium, thorax, abdomen and open wounds of joints. The volume of blood removed from wounded soldiers was quite staggering, notwithstanding that they had probably lost a great deal anyway before coming under medical care. That great military surgeon, George James Guthrie ${ }^{6}$, with unrivalled experience in the Peninsular, was an ardent believer in venesection-"if local inflammation and symptomatic fever run high both are to be moderated by blood-letting every six to eight hours". He agreed with Alexander Copland Hutchison, his naval contemporary, that bleeding was beneficial in erysipelas and hospital gangrene. The books of Guthrie and Hennen record with fascinating clinical detail many wounds which even today one might feel happy to have cured, despite that fact that the patients were being exsanguinated rather than transfused. An officer of the Royal Dragoons suffered a penetrating wound of the knee joint at two o'clock on the day of Waterloo. Under the care of Dr. Hennen ${ }^{7}$, it was estimated that by bleeding and leeching he lost no less than $250 \mathrm{oz}$. of blood during this treatment, yet he made a good recovery.

Despite the exhortation that, in certain wounds, bleeding can hardly be too profuse, it was generally stressed that it was undertaken to prevent inflammation which, once established, no amount of bleeding would prevent. Discretion and timing were required. When Queen Anne's only surviving child of eleven, the Duke 
of Gloucester, was bled for smallpox, Dr. John Radcliffe observed that his attendant physicians had thereby slain him. And it was suggested that repeated bleeding during the pregnancy of Princess Charlotte contributed to. her untimely death after labour, which changed the course of British history, for Victoria might not have succeeded to the throne. In the seventeenth and eighteenth centuries at the end of summer campaigning, when the troops were "exhausted or labouring under a camp disease, bleeding for wounds could loosen entirely the little hold they might have on life"s. Officers on the other hand, "well fed and warmly clothed, riding a pleasant journey would bear bleeding well".

Two days after the great victory of Blenheim in 1704, the stresses and exertions of the campaign had resulted in what the Duke of Marlborough called a "heating of the blood" and for this he was bled with relief".

\section{Accidents from venesection}

Since venesection was resorted to so frequently on the slightest of indications and often performed by midwives, gardeners, blacksmiths and unskilled surgeons, accidents were by no means unknown, and these varied from ecchymosis, injuries to nerves and tendons, opening of an artery, aneurysms, and death from haemorrhage or infection. Reece $(1807)^{10}$ relates how a blacksmith in Herefordshire bled his wife for "some slight indispositions" but unfortunately penetrated the brachial artery and she died of mortification.

Phlebitis and pyaemia were occasional complications and John Hunter ${ }^{11}$ recorded such a case after dissecting the arm of a patient who had died of this cause in St. George's Hospital. He had previously noted inflamed veins and abscesses in horses, for it was no uncommon thing for ostlers to bleed their charges up to 10 pints, even when in perfect health.

\section{Method of venesection}

Heister $^{12}$ in his well known General System of Surgery (1748) gives a vivid account of the operation. "A good phlebotomist should have a steady, nimble and active hand with a sharp eye, without which he may miss the vein or commit some accident". Although a vein in the arm was most usually chosen, it was deemed by some that the vessel opened should be as near as possible to the inflamed tissue, and veins in the hand, foot, temple, neck or even penis in venereal disease were used. Much notice was taken of the appearance of the blood and the thickness of the buffy coat as an indication of the degree of inflammation and the advisability for yet further bleeding.

\section{Leeching}

When venesection was not practical, leeches were employed, each leech being said to remove as much as an ounce of blood. The greatest exponent of leeching was a Frenchman, Broussais, who had served in Napoleon's campaigns and was subsequently appointed as assistant professor at Val de Grace Military Medical School. Under his guidance, the doctors of Paris leeched as they had never done before and often ordered them to be applied to newly-admitted patients before they had even been seen. In the year 1833, forty-one million leeches were said 
to have been imported into France. They were used in the Crimean War but consignments from Constantinople were often dead on arrival. Even in my own lifetime, as a house-physician my chief once prescribed the application of leeches over a tender liver. They were sent up from the dispensary and encouraged to attach themselves with a little milk and sugar on the skin.

\section{Decline of venesection}

Whatever the merits or demerits of venesection and blood-letting generally, between 1850 and 1865 it gradually ceased to be the universal remedy and was playing a very minor role in therapy. It is difficult to understand quite why it happened just then, for the quality of intellect and observation cannot have been very different to that of the great physicians of past centuries. Statistical methods played a part for Skoda in Vienna and Louis in Paris-both recorded more survivals from pneumonia without venesection. In the Crimean War few of the wounded were bled, for a different reason, however, since they were so reduced by hardship as not to stand bleeding well.

In 1877 Sir Thomas Longmore ${ }^{13}$, Professor of Surgery in the Army Medical School, wrote in "Gunshot Injuries" that "few modern surgeons believe such a drain on the circulation to be beneficial, much less necessary, and that the greatly reduced mortality of hospital gangrene may be due to the abandonment of the practice of bleeding". The writings of Louis from France and Marshall Hall in England and many articles in American journals during the 1870s and 1880s, agreed that venesection should be given up. During the American Civil War, the Confederate Surgical Manual condemned "the time-honoured absurdity of venesection". Nevertheless, the idea still had some adherents into this century. In the first edition of his Practice of Medicine, Sir William Osler recommended that "timely venesection saves life in pneumonia" and this was repeated in the eighth edition in 1912. At the present day there are probably only three valid indications for venesection-right heart failure, polycythaemia and haemochromatosis.

At the end of a long era of two thousand years or more, one wonders how a method of treatment could have been pursued had it invariably inflicted more harm than good on the wounded soldier or sick civilian. Were the observations invariably wrong? So strong is our belief in custom and tradition, one has a sneaking feeling that perhaps venesection was not after all the biggeest nontreatment or confidence trick of all time. All the evidence is really against such a thought however, and it is highly suspicious that one method could have been so uniformly beneficial for so many complaints! A cynical judgement would be that we must never have a therapeutic vacuum and that the value of venesection lay in doing something dramatic, however ineffectual. Looked at in terms of the physiology and pathology of severe haemorrhage as we understand them today, various changes in the body result (Table 1 ) and it is difficult to conceive how these can have helped in the battle against the almost inevitable infection of wounds. In retrospect it is probable that most venesections did not do any great harm; in some instances such as illness in plethoric overweight patients, heart failure and head injuries, it might, as now, have done good, but for many wounded in battle the added loss of blood must have been the final straw and have greatly 
Table I

Physiological effects of haemorrhage

\begin{tabular}{|l|l|l|}
\hline \multicolumn{1}{|c|}{ Reduce } & \multicolumn{1}{c|}{ Stimulate } & \multicolumn{1}{c|}{ No change } \\
\hline Blood pressure & Steroids & Immune bodies \\
Blood volume & Catecholamines & \\
Red cell mass & Clotting factors & \\
O, Carrying capacity & Platelets & \\
& W.B.C. & \\
& Fibrinolysins & \\
\hline
\end{tabular}

increased mortality, for the concept of blood volume in the cause of shock was as yet unknown and to be learned three hundred years later. For the military historian the question of its value in preventing infection must, however, be much more difficult and leaves a question that I am unable to answer.

\section{Transfusion}

Despite the obsession of past centuries in depriving the sick and injured of their life's blood, our forebears were not wanting in their endeavours to transfuse blood into exsanguinated patients, or more hopefully to cure disease or rejuvenate the aged.

The idea of blood transfusion became possible after Harvey's discovery of the circulation of the blood but it remained an idea despite many claims of priority until Dr. (later Sir) Christopher Wren, among his many achievements, showed that various fluids could be successfully injected into the blood stream. This preceded Dr. Richard Lower's experiment in Oxford of transfusing blood from the artery of one dog into the vein of another in 1666; and, in the next year, a Frenchman named Denys in Montpellier transfused the blood of a lamb into a man, thus gaining priority for the first human transfusion.

Later that year Samuel Pepys "was pleased to see" a patient who, a week previously, had been transfused with about $12 \mathrm{oz}$. of lamb's blood by Dr. Lower. The subject was a poor, debauched man, by name Arthur Coga, a Bachelor of Divinity of Cambridge, who was "cracked a little in the head". He was paid twenty shillings for "suffering the experiment and found himself much better for it".

Transfusion remained something of a scientific curiosity for two centuries, partly due to the lack of knowledge of incompatibility, the technical difficulty of transferring blood without hollow needles, cannulae, and tubing, and last but not least the impossibility of preventing blood clotting. In fact, it was probably the latter difficulty which prevented any but homeopathic amounts of blood being transfused, thereby preventing death due to incompatibility.

If French Military surgery had been supreme in the Napoleonic Wars and that of the British Empire in the First World War, Prussian Military surgery was certainly the best in the second half of the nineteenth century. The cream of German surgeons ministered to the Prussian armies in Bismark's wars against Denmark, Austria and, finally, in the Franco-Prussian War of 1870. They had 
quickly adopted Listerian methods and now, once again, attempted blood transfusion by employing defibrinated blood.

If the founding of the German Empire at Versailles in 1871 was almost as if the old Holy Roman Empire of Charlemagne had been revived, the art of blood transfusion had not. In the first edition of his Military Surgery (1878) Friedrick v Esmark ${ }^{14}$ had advised the transfusion of defibrinated, warm, filtered blood, but in the third edition of 1888 , he was honest enough to admit the dire consequences, with haemoglobinaemia and haemoglobinuria, which were generally fatal. Every form of transfusion was rejected and intravenous saline wisely advised instead.

Nevertheless Esmark's contributions to Military Surgery were considerable, he introduced the first Field Dressing, the triangular bandage and the method of compressing the limbs with rubber bandages to concentrate blood in the vital organs, a procedure which was named autotransfusion.

\section{The Boer War}

In the Boer War, in which the newly created Royal Army Medical Corps was first engaged with such distinction, venesection had been abandoned and transfusion was not yet practicable. But, in 1901, the year in which the War ended, an epochmaking discovery was made by a Viennese pathologist, Karl Landsteiner, who announced, in a modest paper, the discovery of iso-agglutination and the A.B.O. blood groups. For a number of years little attention was paid to his work, and it was not until thirty years later that Landsteiner received the Nobel Prize in Medicine. However, blood grouping was used in New York in 1906 in the classic experiments and successful transfusion by Carrel with arterial anastomosis, though this was far too technical a procedure for most surgeons to master.

Various other methods of transfusion of whole blood had a limited vogue, notably the Kimpton-Brown tube, the Keynes flask, and the rotary pump. As a registrar, the writer had occasion to use a Kimpton-Brown tube, which was coated inside with hot paraffin wax, filled from the donor's vein and carried to the recipient. The rotary pump compressed a rubber tube between the vein of the donor and that of the recipient and presented no great difficulties. I have used this method several times to transfuse fresh blood and, during the War, assisted a French medical officer from a North African regiment to carry out such a transfusion. All went so smoothly that he did not even need to take his Gaullois cigarette from his mouth during the operation:

It was not until 1915 that the second great advance in the practicality of blood transfusion was made by the discovery of a safe anticoagulant. Sodium phosphate, oxalate, hirudin and citrate had all been rejected on account of toxicity but, at last, it was discovered independently by Agote in Buenos Aires and by Dr. Richard Lewisohn in New York that a 0.2 per cent solution of sodium citrate is an efficient anticoagulant without toxic effects in doses not exceeding 5g. Dr. Lewisohn, a surgeon to Mount Sinai Hospital, lived for many years to see the great boon his important work had bestowed on mankind. He was a modest and charming man and who is to say he did not, perhaps, deserve a Nobel Prize too? 


\section{First World War}

Two factors had now been established which made blood transfusion safe and practicable - grouping and the feasibility of storage of anticoagulated blood, but the full potential was not recognised or exploited in the treatment of the millions of casualties in the First World War. It was not, however, fair to infer, as is sometimes done, that blood transfusion did not get beyond the stage of an interesting experiment.

In the 2nd and 3rd British Armies on the Western Front, in 1917-1918, citrated blood was stored before offensives and up to $1,000 \mathrm{cc}$ was given. The official works on the Medical Services of the War record the existence of resuscitation teams and transfusion officers ${ }^{15}$. Transfusion was given in divisional areas at special posts for blood transfusion "to save wounded who might die on the journey back from the line". Transfusion was said to treble the recovery rate of desperate abdominal cases, and improved that of compound fractures of the femur. Surprisingly, the blood was not always cross-matched or the patients grouped, but a test dose of 15 to $20 \mathrm{cc}$ was given and, in the majority, no sign of incompatability was noticed. Donation of blood was popular with the troops, since they were rewarded by three-weeks leave in the United Kingdom.

The names of Bruce Robertson, a Canadian, Oswald Robertson, an American, Kenneth Walker, an Englishman and Holmes a'Court, an Australian, are all associated with the awakening of interest in the feasibility and in the practice of Blood Transfusion. The lessons learned then were clearly stated but had to be relearnt in the next conflict-namely, in severe haemorrhage, the proper substitute for blood is blood. If in doubt, transfuse and err on giving too much rather than too little.

In the inter-war years the introduction in 1926 by Hendon and Matas in the United States of America of continuous intravenous saline led to the final breakthrough in the practice of blood transfusion. Previous transfusions were seldom more than one pint, which one would now regard not only as homeopathic but almost unjustifiable. In $1935 \mathrm{H}$. L. Marriott and Alan Kekwick ${ }^{16}$, resident surgical officer and house physician respectively at the Middlesex Hospital in London, introduced massive transfusion of blood by the continuous drip method, initially for chronic anaemias, so as not to overload the circulation, but also for massive haematamesis. Many of these latter cases came under the care of Sir Gordon Gordon-Taylor, whose house surgeon I was at the time. We bled the donors, usually the patient's relatives, cross-matched the blood against standard sera on a small white tile and kept the blood in milk bottles in the ward refrigerator. The blood was poured into a large glass reservoir and oxygen bubbled through it to prevent sedimentation of the red cells. If relatives were not available for bleeding, donors were provided by the London Blood Transfusion Service, the first voluntary organisation or donors in the world, formed in 1921 by Mr. P. L. Oliver who became its Secretary under the aegis of the British Red Cross. Such was the beginning of the massive transfusion of as much whole blood as the patient required. 


\section{World War Two}

The experiences of the Spanish Civil War in the value of blood transfusion had not gone unnoticed and, after the Munich Crisis, detailed discussions and plans were formulated to establish Ministry of Health Blood Depots and an Army Blood Transfusion Service: The story of the achievements of this organisation, under the direction of Brigadier Sir Lionel Whitby, will be known to many of you. In essence, the Army took over the entire collection, processing and distribution of blood, blood products, and other intravenous fluids for its own use. Being a perishable and potentially lethal biological fluid, blood required its own specially trained personnel for its transport and administration and the service did not rely on the usual channels of Army Supply. The Royal Army Medical Corps entered the War with a fully-operational plan and the means of supplying large quantities of blood and blood products.

Lionel Whitby was no newcomer to the experience and benefits of blood transfusion. As an artillery officer he was gravely wounded in March 1918 and was transfused prior to a very high amputation through the thigh.

During the course of the War in Europe, the British Army Blood Transfusion Service bled three quarters of a million donors and supplied blood products to units as far distant as Iceland, Capetown and Malaysia ${ }^{17}$. The method whereby plasma and serum could be freeze-dried was developed by R. I. N. Greaves, then Reader in Bacteriology, and later Professor of Pathology in Cambridge University, and this formed the basis of all large scale plants for the drying of transfusion fluids in the United Kingdom, the United States of America and Canada during the War.

Different views were held as to the relative merits of whole blood and plasma. Since the latter is more easily stored and transported the official opinion was at first in favour of its more extensive use. Clinical experience later in the War and the recognition of homologous serum jaundice caused some modification in its employment and its value became rather under-estimated.

As a first aid measure, however, it is essential to preserve life with plasma, until the casualty can be evacuated to a point at which whole blood can be given. Blood is the fluid of choice for battle casualties to make them fit for surgerythe ultimate aim of resuscitation.

The Campaigns in the Western Desert in 1940-1942 and the air-raid casualties in the cities at home provided much experience in resuscitation and the name of Lieutenant-Colonel G. A. H. Buttle, director of the Army Blood Transfusion Service in the Middle East, will long be remembered for his support of the forward surgeons and advocacy of blood. Ten per cent of the wounded in the Desert required transfusion, the average requirement being 2.9 pints and more pro rata in the more severely wounded, some four to five pints in abdominal injuries. In B.L.A. in Europe the supplies of blood were so plentiful that the average transfusion was four pints - two-and-a-half blood, one-and-a-half plasma; it was thought that some wounded were lucky to escape a transfusion but, actually, the rate was only one in ten, as in other theatres. The value of skilled transfusion officers was everywhere manifest and welcomed and they added a new dimension in the care of the seriously wounded. Nevertheless, there are situations in wartime 
when a medical unit is isolated or where, by the nature of the military operation, blood cannot be supplied. Under such circumstances some tubes of standard grouping sera, sets for taking blood and the knowledge of how to use them could be invaluable. It is advantageous, even nowadays, for forward surgeons to be prepared for all eventualities.

\section{American blood program ${ }^{18}$}

By their own admission, the Americans got off to a slow start in planning for the supply of blood for military casualties and, when precipitated into the War in 1941, there was no blood bank contemplated or planned. Too much emphasis had been laid on the value of plasma and the idea of bleeding local donors in combat areas which, in fact, did not work too well in North Africa, nor had the experience of the British in the previous campaigns in the Western Desert been sufficiently heeded in official circles.

Nevertheless with characteristic vigour and ingenuity, the problems were identified and a blood program instituted which, for quantity and distance, eventually eclipsed all previous records. After "D" Day, blood was first lifted to landing strips, and later to Le Bourget in Paris. After August 1944, blood was flown daily from the United States to Prestwick en route to France and later directly to Orly. As the War had progressed, the blood program of the United States Medical Corps became truly global. In the South. West Pacific in the eleven months from November 1944 to September 1945, 181,555 units of whole blood were flown from America, 25,000 pints being supplied for the Okinawa operation alone.

The details of this "milk round" of blood to all theatres of war throughout the world are largely logistic and the magnitude of the effort can be appreciated when it is realised that over thirteen million donations of blood were given voluntarily to the Blood Donor Service of the American Red Cross during the years they were at War. Its clinical use seems to have differed from British practice only in the liberality with which whole blood was employed. In the Luzon Campaign in the Philippine Islands "blood was administered to all patients with severe or moderately severe wounds or with evidence of impending shock regardless of their status on admission. Those with no shock received two pints, those in moderate shock four to six pints run in rapidly by gravity". This certainly was rather more than British surgeons would have used but the results achieved in survival by American surgery seem to justify their practice.

The War in Vietnam, fought 8,000 miles from the Home Bases in America, provided very different problems, militarily and medically, from the previous wars in Europe and the Middle East. A hospital mortality rate of 2.6 per cent compared with 4.5 per cent in World War II and 2.5 per cent in Korea resulted from the rapid evacuation of casualties by helicopter, the ready availability, indeed lavish supply of blood, and the excellence of the Base Hospitals where primary surgery was performed.

In 1968 and 1969 no less than a third of a million units of blood were flown annually from New Jersey via Alaska and Japan to the Central Blood Bank in 
Vietnam ${ }^{19}$-a long way geographically and a long way in practice since the tentative beginning of transfusion in the trenches in 1918.

\section{Present and future practice}

In the past forty years blood transfusion has evolved from a single unit of about one pint, now regarded as almost homeopathic and unjustifiably dangerous, to the use of much larger volumes in general, and on occasion massive transfusions of up to eight times the patient's original blood volume. Having become so used to liberal supplies of blood during war-time, the demands on the National Blood Transfusion Service have increased annually despite exhortations for economy. Though it is almost easier in National Health Service hospitals to order a bottle of blood than one of beer, the supply has happily always kept pace with demand without question or cost to the National Health Service and private patients alike. The National Blood Transfusion Service is a large employer of skilled doctors and technicians, and in England and Wales processes annually some two million units. In the writer's own region, Oxfordshire, which is one of the smaller ones, 160 people are employed and 120,000 donors are bled each year. Clinical transfusion practices have remained unchanged for a relatively long period of thirty years but, in the words of a haematologist, "This inactivity is at an end". The science of blood transfusion and blood products is now so vast that it has become a subject largely for the expertise of specialists and has far outstripped the knowledge of the average surgeon and certainly of the writer.

For most of us, blood transfusion has meant whole blood, but in the last two decades haematologists have become more concerned with separating and conserving the many different and valuable factors in blood and only transfusing those ingredients which are lacking in any particular situation. Fig. 1 outlines the products which are obtained by fractionation.

Frozen red cells have particular use in the creation of banks of rare groups, for renal dialysis, in autotransfusion for example in Jehovah's witnesses, and also in accident and military surgery. Plasma protein fraction is without the hazards of Hepatitis B since each individual donation is now screened for Australia-antigen and it can be stored for two to three years. It is the fluid of choice where previously dried plasma was given.

Since blood is so easily replaceable, it is important that we should not become complacent or careless about blood-loss during or after operation. Our anaesthetic colleagues are probably the best judges of the actual amount lost and generally consider that it is greater than the surgeon would care to admit.

The two greatest exponents of meticulous haemostasis were Halsted in Baltimore and Moynihan in Leeds. Blood transfusion was not available when Halsted introduced his radical amputation of the breast, nor did his followers use it in the United Kingdom when that operation was in vogue. Despite the extent of the operation and the considerable blood loss, post-operative deaths were practically unknown. A foreign visitor in Lord Moynihan's operating theatre, observing the most punctilious care over haemostasis, was once heard to remark, "Is English blood then so precious?" The answer now must be that all blood is precious, whether at the time of operation or in the use of voluntarily and anonymously 


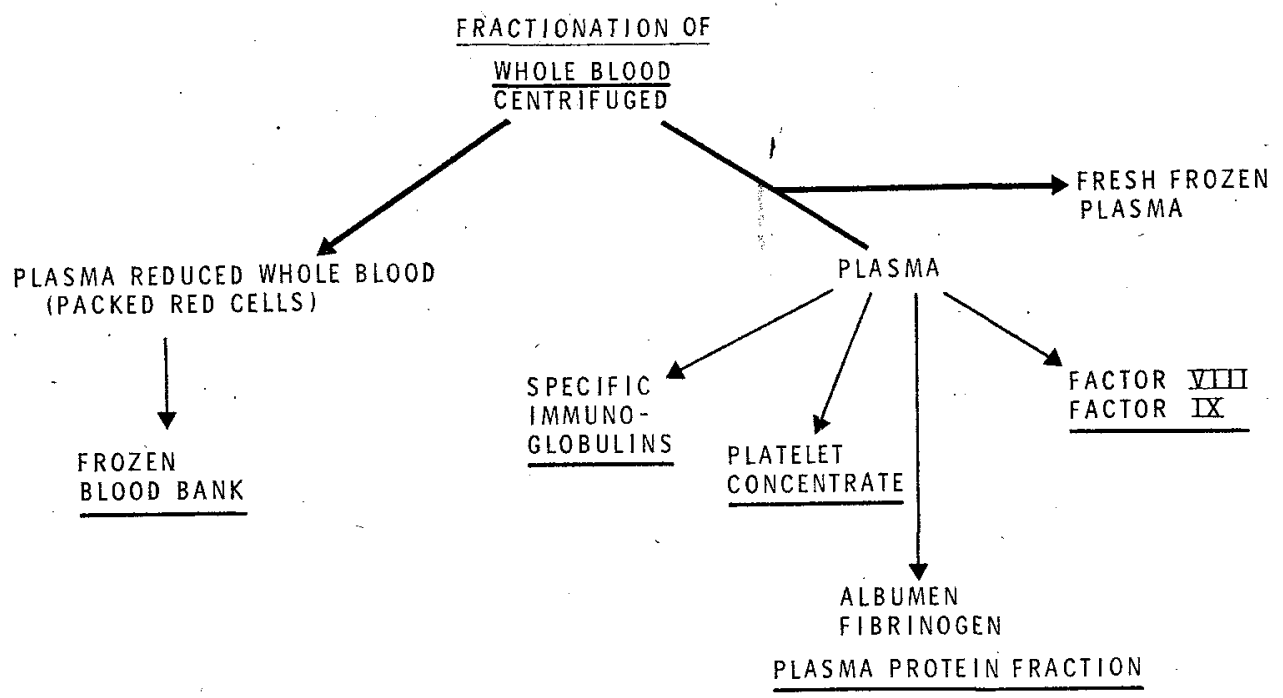

Fig. 1. Fractionation products of whole blood

donated blood for transfusion afterwards. There is some evidence too that operating on patients with a low haemoglobin is not so hazardous as we once thought alid that "topping-up" transfusions may not always be wise. One day we may have synthetic fluids capable of transporting oxygen in the body and some attempts have already been made by the Japanese in this field. Should that ever happen, we may well look back on the present era of blood transfusion with all its complexities and potential dangers with as much incredulity as we now regard venesection as a treatment for inflammation.

\section{Massive transfusion}

The introduction of massive transfusion-that is anything over 10 pints has brought in its wake a variety of new and baffling problems, some of which are listed in Table II. Whilst a proportion of these are clinically recognisable,

\section{Table II}

Hazards of massive blood transfusion

(Clinics in Haematology Vol. 5. 1976)

\begin{tabular}{|l|l|}
\hline \multicolumn{1}{|c|}{ Metabolic and related } & \multicolumn{1}{|c|}{ Transmitted } \\
\hline Citrate toxicity & Hepatitis B \\
Coagulation abnormalities & Hepatitis A \\
Altered Hb function & Bacterial \\
Hypothermia & Clerical accidents \\
Micro embolism & Subtle mismatch \\
Plasticiser toxicity & Inter-donor incompatibility \\
Denatured proteins & \\
Infusion of vaso-active substances & \\
Hyperkalaemia & \\
Elevated $\mathrm{PO}_{4}-\mathrm{NH}_{4}$ & \\
\hline
\end{tabular}


many can obviously only be diagnosed with the help of specialists and laboratory studies, which one is unlikely to find in forward surgery in the field.

One of the most dramatic and alarming complications to face military surgeons is when the massively transfused patient suddenly begins to bleed from every wound surface and orifice. This is now known variously as the oozing, tomato juice, red ink or defibrination syndrome. The situation emphasises the fact that, despite all artery forceps, ligatures, and diathermy, the successful outcome of all operations - depends in the last resort on the normal coagulation of blood in thousands of capillaries.

These coagulopathies appear to result not only from the total absence of platelets and factors VIII and IX in stored blood, but also from the disturbance of clotting mechanisms in massive transfusions. Disseminated intravascular thrombosis is one recently recognised condition which despite its name paradoxically results in bleeding. It is suggested that abnormal intravascular aggregates use up the available coagulation factors, leaving none for the normal processes of clotting elsewhere. Since the causes are probably multiple and not easily identified, there is no agreement about treatment-fresh blood, fresh frozen plasma, cortisone, heparin and prayer have all been used with varying success.

Citrate toxicity has been known and discussed ever since its adoption for anticoagulation. Toxicity due to pure overdose of citrate is rare but its effect in massive transfusion by binding ionised calcium results not only in oozing but, secondarily, in potentiating high potassium levels, and this may be lethal by. precipitating arrhythmias and hypotension. The metabolism of citrate may be affected by hypotension, cold, and depressed liver function, all of which are likely to be present in battle casualties. Although it is commonly given, the empirical administration of calcium gluconate in oozing wounds may be equally hazardous.

It is difficult to hazard a guess as to what form the Army Blood Transfusion Service may take in any future major war, but it is highly probable that the plans will differ from those in previous conflicts. Jeffery ${ }^{20}$ in the Corps Journal in 1974 laid down the basic principles which should be followed in what might be a thermo-nuclear war. These are logistic isolation, dispersal of resources, and flexibility, with the possible use of frozen banked red cells. By reviewing the past history of transfusion, and the abandonment of venesection which had so long held the field, a background has been given to the methods which are so vital in modern surgery, and whereby many lives may be saved in peace and war. Such was the purpose of the surgeon after whom this lecture is named.

\section{Acknowledgements}

My grateful thanks are due to Dr. Alan Sharp, Department of Haematology, Radcliffe Infirmary, Oxford, to Dr. M. M. Fisher, Deputy Director of the Oxford Regional Blood Transfusion Service for much specialised information, to Colonel .J T. Joy, Medical Department, United States Army, for advice and the generous gift of official publications concerning Blood Transfusion and to Mr. E. Cornelius, Librarian of the Royal College of Surgeons and the Staff of Cairns Library in Oxford, for their most willing help. 


\section{REFERENCES}

1. The English Army in France. The Personal Narrative of an Officer. (1830). Vol 1. p. 164. Colburn and Bentley, London.

2. Dover, T. (1742). The Ancient Physician's Legacy to His Country. 6th ed. p. 101. Kent, London.

3. Hunter, J. (1974). A Treatise on the Blood, Inflammation and Gun-shot Wounds. lst ed. p. 564. John Richardson for George Nicol. London.

4. Pringle, J. (1753). Observations on Diseases of the Army. 2nd ed. p. 129. Wilson and Dunham. London.

5. Ballingall, G. (1852). Outlines of Military Surgery. 4th ed. p. 135. Black, Edinburgh.

6. Guthrie, G. J. (1827). Treatise on Gun-shot Wounds. 3rd ed. p. 237. Burgess and Hill. London.

7. Hennen, J. (1820). Principles of Military Surgery. 2nd ed. p. 151. Constable, Edinburgh.

8. BELL, J. (1800). Discourses on the Nature and Cure of Wounds. p. 244, Mundell, Edinburgh.

9. Churchill, W. S. (1947). Marlborough. His Life and Times. Book 1. p. 896. Harrap. London.

10. REECE, R. (1807). Medical Guide. 4th ed. p. 111. Longman. London.

11. Hunter, J. (1973). Transactions of the Society for Improvement of Medical and Surgical Knowledge. p. 18. Johnson. London.

12. Heister, L. (1784). A General System of Surgery. 3rd ed. p. 275. London.

13. LONGMORE, T. (1877). Gun-shot Injuries. p. 406. Longman. London.

14. ESMARK, F. (1878). The Surgeon's Handbook on the Treatment of Wounded in War. Translated by Clutton. p. 165 .

15. GORDON-TAYLOR, G. (1931). Chapter on Blood Transfusion Medical History of the Great War, H.M.S.O. London.

16. MarriotT, H. L. and KeKWICK, A. (1935). Lancet ii, 193.

17. WhItby, L. (1953). Chapter on Blood Transfusion. History of the Second World War-Surgery. H.M.S.O. London.

18. Blood Program in World War II. (1964). Ed. by Kendrick, D. B. Medical Department, United States Army, Office of the Surgeon General. Washington, D.C.

19. Medical Support for the United States Army in Vietnam 1965-1970. (1973). Ed. by Spurgeon Neel. Department of the Army. Washington, D.C.

20. JefFreY, H. C. (1974). Blood Transfusion in War. J. roy. Army med. Corps. 120, 24.

\section{QUEEN MOTHER}

On the occasion of the birthday of Her Majesty The Queen Mother the following telegram was sent:-

"Representative Colonel Commandant and All Ranks Royal Army Medical Corps with their humble duty send their greetings to Her Majesty The Queen Mother their Colonel in Chief on her birthday." 